\title{
Editorial
}

Dermatology 2006;212:214-215

DOI: $10.1159 / 000091246$

\section{The Importance of Thrombosis in Patients with Lupus Erythematosus}

\author{
Dan Lipsker
}

Clinique Dermatologique et Faculté de Médecine, Université Louis-Pasteur, Strasbourg, France

Much progress has been made during the last two decades in the knowledge of factors involved in the prognosis of patients with lupus erythematosus (LE). After 5 years of evolution, morbidity and mortality in patients with LE are essentially related to side effects of treatments, infections and thrombosis [1]. Infections and treatment-related side effects are well-known to most clinicians, but the importance of thrombotic complications is often underestimated. Thrombosis, whether in the context of lupus anticoagulant and/or antiphospholipid antibodies or not, is an important factor that should not be neglected. Both arterial and venous thrombosis may occur, and LE itself is a significant risk factor for ischemic heart disease and atheromatosis [2-4]. Many clinical signs indicative of thrombosis are skin findings that can occur simultaneously, after or before the onset of serious, sometimes life-threatening, thrombotic events. Thus, the recognition of cutaneous signs indicative of thrombosis in patients with LE is of major importance. Yet, though those signs are well known, their importance is not stressed in the current classification of cutaneous findings in patients with LE [5-7].

Clinical signs indicative of thrombosis in patients with LE are illustrated in table 1 . The clinical significance of some of these signs is unequivocal as for example the white, ivory-colored, atrophic papules with peripheral tel-
Table 1. Cutaneous signs found in patients with LE indicative of - or possibly related to - thrombosis

Degos-like disease

Atrophie-blanche-like lesions

Cutaneous necrosis

Splinter hemorrhage

Livedo, especially racemosa-like

Telangiectasis

Purpura, especially noninfiltated, stellar purpura

Anetoderma

Thrombophlebitis

Ulcerations

angiectasis called 'Degos disease-like lesions' which always indicate thrombosis [8]. Histopathologically, a cone-shaped cutaneous infarct is found, and these lesions can therefore be interpreted as the clinical consequence of an arteriolar cutaneous infarct. The interpretation of some other signs is more ambiguous, but their presence should raise suspicion of ongoing thrombosis, unless another mechanism can be proven. Purpuric macules and periungual telangiectasis are examples of such findings.

The presence of these lesions involves the search for thrombosis in other sites, the search for cardiac valvular disease as well as the search of known thrombotic predis-

\section{KARGER}

Fax +41613061234

E-Mail karger@karger.ch

www.karger.com
(C) 2006 S. Karger AG, Basel

$1018-8665 / 06 / 2123-0214 \$ 23.50 / 0$

Accessible online at: www.karger.com/drm
D. Lipsker

Clinique Dermatologique

1, place de l'Hôpital

FR-67091 Strasbourg Cedex (France)

Tel. +33 388116179 , Fax +33388115962, E-Mail dlipsker@noos.fr 
posing factors, especially those with a therapeutic consequence such as hyperhomocystinemia or the presence of antiphospholipid antibodies. Patients should stop cigarette smoking, especially as cigarette smoking is also associated with cutaneous LE [9-11]. Women in child-bearing age should use adequate contraception, avoiding highly dosed oral contraceptives. Lipid levels should be closely monitored and lowered if necessary. Indeed, these cutaneous lesions raise, merely by their presence, the question if an anti-platelet-aggregating treatment should be started, as they are direct evidence of thrombosis. It is therefore important in clinical practice to identify these signs because of their diagnostic, prognostic and therapeutic consequences.

\section{References}

1 Cervera R, Khamasta MA, Font J, Sebastiani GD, Gil A, Lavilla P, et al: Morbidity and mortality in systemic lupus erythematosus during a 10-year period: a comparison of early and late manifestations in a cohort of 1,000 patients. Medicine 2003;82:299-308.

2 Roman MJ, Shanker B-A, Davis A, Lockshin MD, Sammaritano L, Simantov R, et al: Prevalence and correlates of accelerated atherosclerosis in systemic lupus erythematosus. N Engl J Med 2003;349:2399-2406.

3 Asanuma Y, Oeser A, Shintani AK, Turner E, Olsen N, Fazio S, Linton MF, Raggi P, Stein CM: Premature coronary-artery atherosclerosis in systemic lupus erythematosus. N Engl J Med 2003;349:2407-2415.
4 Ohlenchlaeger T, Garred P, Madsen HO, Jacobsen S: Mannose-binding lectin variant alleles and the risk of arterial thrombosis in systemic lupus erythematosus. N Engl J Med 2004;351:260-267.

5 Gilliam JN, Sontheimer RD: Distinctive cutaneous subsets in the spectrum of lupus erythematosus. J Am Acad Dermatol 1981;4:471475.

6 McCauliffe DP: Cutaneous lupus erythematosus. Semin Cutan Med Surg 2001;20:14-26.

7 Sontheimer RD: The lexicon of cutaneous lupus erythematosus - A review and personal perspective on the nomenclature and classification of the cutaneous manifestations of lupus erythematosus. Lupus 1997;6:84-95.
8 Stephansson EA, Niemi KM, Jouhikainen T, Vaarala O, Palosuo T: Lupus anticoagulant and the skin: a long-term follow-up study of SLE patients with special reference to histopathological findings. Acta Derm Venereol 1991;71:416-422.

9 La Vecchia C, Gallus S, Naldi L: Tobacco and skin disease. Dermatology 2005;211:81-83.

10 Miot HA, Bartol Miot LD, Haddad GR: Association between discoid lupus erythematosus and cigarette smoking. Dermatology 2005; 211:118-122.

11 Lipsker D, Boeckler P, Hauptmann G: Cigarette smoking and lupus erythematosus. Dermatology 2006;212:263. 